\title{
A Gastric Subepithelial Tumor with a Positive Pillow Sign
}

\author{
Gwang Ha Kim ${ }^{1,2}$, Do Youn Park ${ }^{3}$ \\ Department of Internal Medicine, Pusan National University School of Medicine ${ }^{1}$, Biomedical Research Institute, Pusan National University \\ Hospital ${ }^{2}$, Department of Diagnostic Pathology, St. Mary Pathology Laboratory ${ }^{3}$, Busan, Korea
}

Question: A 52-year-old man presented with a gastric subepithelial tumor, which was incidentally found during a heath checkup endoscopy. On upper endoscopy, a subepithelial tumor, approximately $2.5 \mathrm{~cm}$ in size, was found in the lesser curvature of the gastric antrum (Fig. 1A). When pressed with biopsy forceps, the tumor was easily compressed (positive pillow sign) (Fig. 1B). EUS showed a $1.9 \times 1.3 \mathrm{~cm}$-sized well-demarcated heterogeneously hypoechoic lesion with peripheral haloes in the muscularis propria layer (Fig. 1C). Dynamic contrast-enhanced abdominal CT demonstrated high enhancement of the tumor with the same level of enhancement as the portal vein in the arterial phase, with persistence of enhancement in the portal phase (Fig 2).

What is the most likely diagnosis?
Answer: Based on the EUS and CT findings, the tumor was presumed as a glomus tumor rather than a gastrointestinal stromal tumor. Laparoscopic wedge resection was performed for the treatment. Histopathologically, the tumor was highly vascular with thin-walled vessels (Fig. 3A). The vessels were surrounded by monomorphic, small, round-to-polygonal cells forming nests, sheets, and strands. The tumor cells had centrally located nuclei, inconspicuous nucleoli, and clearto-eosinophilic cytoplasm with sharply defined cell borders (Fig. 3A, boxed area). Immunohistochemically, tumor cells were diffusely positive for smooth muscle antigen (Fig. 3B), but negative for c-kit, CD34, desmin, and S-100 protein. Therefore, the tumor was diagnosed as a glomus tumor.

Glomus tumors are benign mesenchymal tumors derived from the modified smooth muscle cells of the glo-
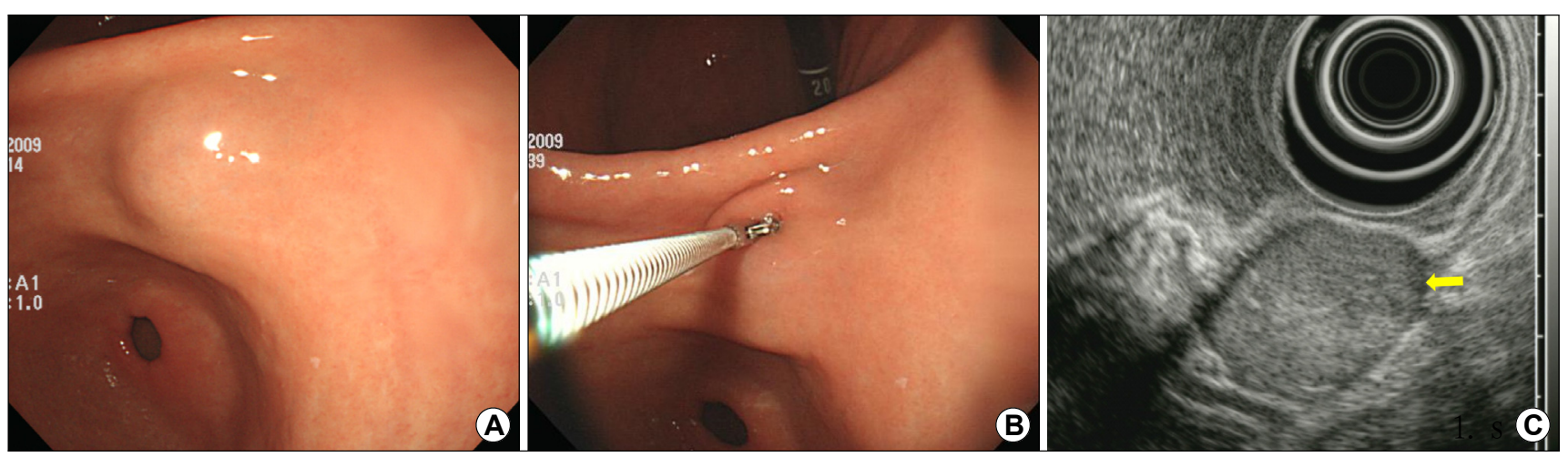

Fig. 1. Endoscopic and endosonographic findings. (A) A subepithelial tumor measuring approximately $2.5 \mathrm{~cm}$ in size is seen in the lesser curvature of the gastric antrum. (B) The tumor is easily compressed when pressed with biopsy forceps. (C) EUS shows a well-demarcated, heterogeneous, and hypoechoic lesion with peripheral haloes (arrow) in the proper muscle layer.

Received: January 11, 2021 Revised: January 14, 2021 Accepted: January 28, 2021

Corresponding author: Gwang Ha Kim

Department of Internal Medicine, Pusan National University School of Medicine and Biomedical Research Institute, Pusan National University Hospital, 179 Gudeok-ro, Seo-gu, Busan Department

Tel: +82-51-240-7869, Fax: +82-51-244-8180, E-mail: doc0224@pusan.ac.kr

Copyright $\odot 2021$ Korean College of Helicobacter and Upper Gastrointestinal Research

(a) The Korean Journal of Helicobacter and Upper Gastrointestinal Research is an Open-Access Journal. All articles are distributed under the terms of the Creative Commons Attribution Non-Commercial License (http:// creativecommons.org/licenses/by-nc/4.0) which permits unrestricted non-commercial use, distribution, and reproduction in any medium, provided the original work is properly cited. 

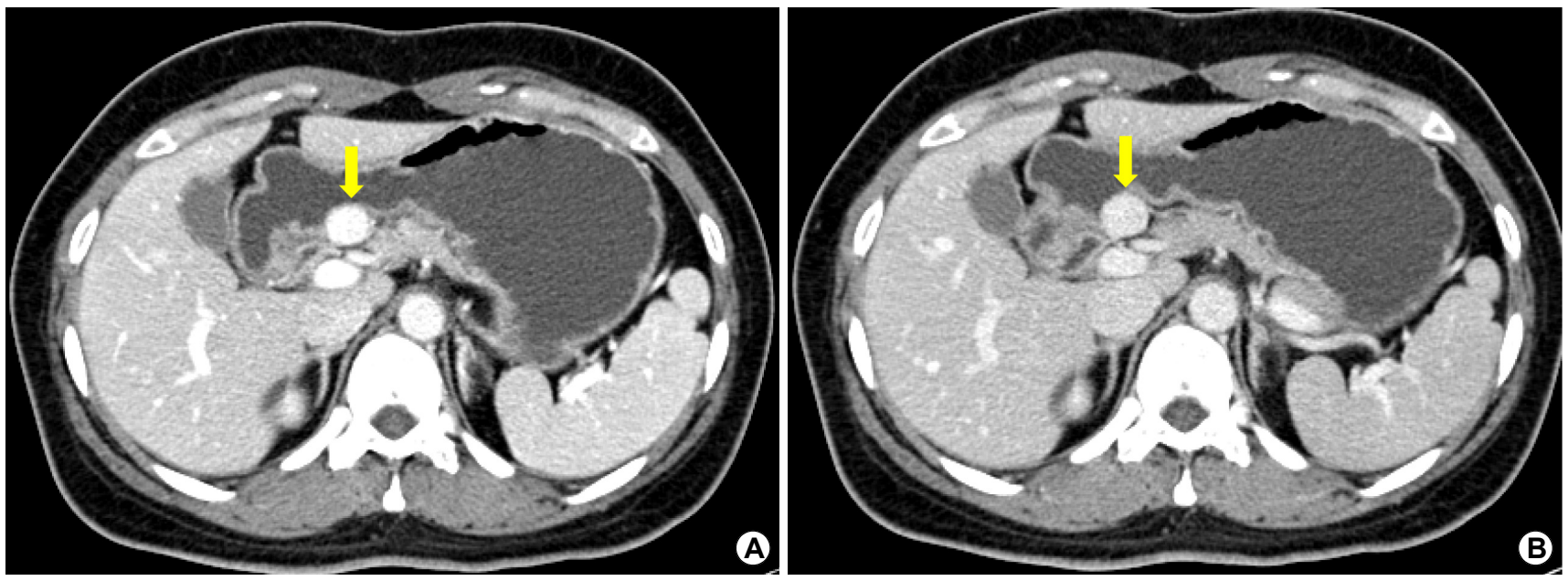

Fig. 2. Abdominal CT findings. (A) Dynamic contrast-enhanced CT of the abdomen showing high enhancement of the tumor (arrow) with the same level of enhancement as that of the portal vein in the arterial phase. (B) This enhancement persists till the portal phase (arrow).
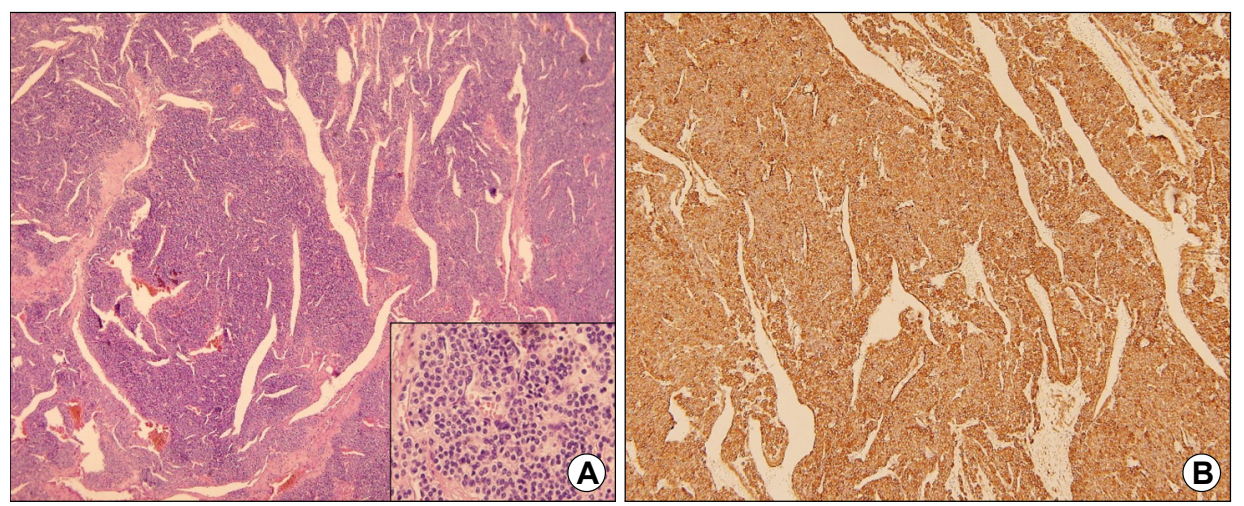

Fig. 3. Histopathologic findings. (A) A highly cellular tumor with monomorphic, small, round-to-polygonal cells forming nests, sheets, and strands $(\mathrm{H} \& \mathrm{E}, \times 40)$. The tumor cells have centrally located nuclei, inconspicuous nucleoli, and clear-to-eosinophilic cytoplasm with sharply defined cell borders (boxed area, H\&E, ×200). (B) Tumor cells are diffusely positive for smooth muscle actin (smooth muscle actin stain, $\times 40$ ).

mus body, which is a type of neuromyoarterial receptor that plays a role in the regulation of arteriolar blood flow. ${ }^{1}$ Although these tumors occur most commonly in the peripheral soft tissues, they also infrequently occur in the gastrointestinal tract. The incidence of gastric glomus tumors is very low, with a gastric glomus tumor-to-gastrointestinal stromal tumor ratio of $1: 100 .^{2}$ Because diagnosis of glomus tumors cannot be definitely confirmed by conventional endoscopy, EUS and CT are commonly used for the differential diagnosis of subepithelial tumors.

Characteristic EUS findings of glomus tumors are heterogeneously hypoechoic lesions with distinct borders in the muscularis propria layer and the presence of prominent peripheral haloes. ${ }^{3}$ Peripheral haloes may be because of the compression of normal muscle tissue of the surrounding muscularis propria by tumor cells. On Doppler and contrast-enhanced EUS, prominent vascular signals can be observed, reflecting the hypervascular nature of the tumor. Characteristic CT findings of glomus tumors show strong enhancement in the arterial phase and prolonged enhancement in the delayed phase during dynamic contrast-enhanced CT. ${ }^{3}$ Both characteristic EUS and CT findings of glomus tumors were present in our case. Presence of pillow sign is reported to be $98 \%$ specific for identification of lipomas, although it is not a very sensitive feature. ${ }^{3}$ Interestingly, the pillow sign was present in our case, which might be a reflection of the presence of a high proportion of vascular components in the tumor. ${ }^{4}$

In summary, although it is difficult to diagnose a glomus tumor preoperatively, the abovementioned characteristic findings of EUS and CT, sometimes observed with a pillow sign, seem useful to differentiate a glomus tumor 
from other mesenchymal tumors.

\section{CONFLICTS OF INTEREST}

Gwang Ha Kim is an editor-in-chief of the Journal but did not involve in the peer reviewer selection, evaluation, or decision process of this article. No other potential conflicts of interest relevant to this article were reported.

\section{ORCID}

Gwang Ha Kim (1) https://orcid.org/0000-0001-9721-5734

Do Youn Park (1) https://orcid.org/0000-0001-7641-1509

\section{REFERENCES}

1. Ha TK, Kim GH, Lee MW, et al. Glomus tumor of the duodenum. Korean J Helicobacter Up Gastrointest Res 2020;20:328-331.

2. Lee HW, Lee JJ, Yang DH, Lee BH. A clinicopathologic study of glomus tumor of the stomach. J Clin Gastroenterol 2006;40: 717-720.

3. Hwang JH, Saunders MD, Rulyak SJ, Shaw S, Nietsch H, Kimmey MB. A prospective study comparing endoscopy and EUS in the evaluation of GI subepithelial masses. Gastrointest Endosc 2005;62:202-208.

4. Baek YH, Choi SR, Lee BE, Kim GH. Gastric glomus tumor: analysis of endosonographic characteristics and computed tomographic findings. Dig Endosc 2013;25:80-83. 